\title{
In-hospital mortality of liver transplantation and risk factors: a single-center experience
}

\author{
Xing-Mao Zhang, Hua Fan, Qiao Wu, Xin-Xue Zhang, Ren Lang, Qiang He \\ Department of Hepatobiliary Surgery, Beijing Chaoyang Hospital, Capital Medical University, Beijing, China \\ Contributions: (I) Conception and design: XM Zhang, Q He; (II) Administrative support: R Lang; (III) Provision of study materials or patients: H \\ Fan, Q Wu, XX Zhang; (IV) Collection and assembly of data: XM Zhang, XX Zhang; (V) Data analysis and interpretation: H Fan, R Lang; (VI) \\ Manuscript writing: All authors; (VII) Final approval of manuscript: All authors. \\ Correspondence to: Qiang He, MD. 8 Gongti South Street, Chaoyang District, Beijing 100021, China. Email: heqiang_cy@163.com.
}

\begin{abstract}
Background: Liver transplantation (LT) is a life-saving treatment for patients with end-stage liver disease and acute liver failure. However, in-hospital death cannot be avoided. We designed this study to analyze patients' in-hospital mortality rate after LT and the factors correlated with in-hospital death.

Methods: The data of patients who received LT in our hospital between January 11, 2015, and November 19, 2019, were obtained from the China Liver Transplant Registry and medical records. The in-hospital mortality rate was calculated, and factors related to mortality, cause of death, and factors related to cause of death were analyzed by reviewing patients' data.

Results: A total of 529 patients who underwent cadaveric LT were enrolled in this study. Modified piggyback orthotopic LT was performed for all patients. Seventy patients died in the hospital after LT, and the in-hospital mortality rate was $13.2 \%$. Factors including model for end-stage liver disease (MELD) score, Child-Pugh grading, intraoperative blood loss, and anhepatic phase were correlated with in-hospital death. MELD score and intraoperative blood loss were determined as the two independent risk factors of in-hospital death. The first two causes of death were infection (34.3\%) and primary non-function (15.7\%). Pulmonary fungal infection was the main cause of infectious death. MELD score was the independent risk factor for infectious death, and both body mass index of donors and cold ischemic time were independent risk factors of primary non-function.
\end{abstract}

Conclusions: In-hospital death poses a threat to certain patients undergoing LT. Our study suggests that the main cause of in-hospital death is an infection, followed by primary non-function.

Keywords: Liver transplantation (LT); in-hospital mortality; risk factor

Submitted Jul 31, 2020. Accepted for publication Nov 09, 2020.

doi: 10.21037/atm-20-5618

View this article at: http://dx.doi.org/10.21037/atm-20-5618

\section{Introduction}

Liver transplantation (LT) is the most effective treatment for patients with chronic end-stage liver disease and acute liver failure. It can also benefit some patients with malignant tumors of the liver. With the development of medicines and the accumulation of experience, recipients' survival rate has improved significantly since the first report of LT by Starzl et al. (1) in 1968. The 1-year survival rate was $82 \%$ in the European Liver Transplant Registry and $87 \%$ in the
Japanese registry, and the 10 -year survival rate ranges from $53 \%$ to $76 \%$ in the American, European, and Japanese registries (2-4).

Despite the rapid developments in LT, in-hospital death threatens a certain percentage of recipients. BennettGuerrero et al. (5) reported that the in-hospital mortality after LT was $8.4 \%$. Gil et al. (6) reported that the overall inhospital mortality was $6.3 \%$, and the mortality of deceased donor LT was $13.5 \%$. In this study, we reviewed the data of patients who received LT at our center to calculate the 
in-hospital mortality and analyze the main death-related factors. We present the following article following the STROBE reporting checklist (available at http://dx.doi. org/10.21037/atm-20-5618).

\section{Methods}

\section{Data collection}

The data of patients who received LT in our hospital between January 11, 2015, and November 19, 2019, were collected and analyzed retrospectively. Clinical data were obtained from the China Liver Transplant Registry and medical records. Cadaveric LT was performed for all these adult patients. Cases of pediatric LT, living donor LT, and multi-organ transplantation were excluded from this study. Recipient information included age, gender, body mass index (BMI), comorbidities, a model for endstage liver disease (MELD) score, Child-Pugh score, causes for transplantation, laboratory variables before and after the operation, operation time, anhepatic phase, and intraoperative blood loss. Donor information included age, gender, BMI, cold ischemic time (CIT), warm ischemic time (WIT), and the last laboratory variables. The study was conducted following the Declaration of Helsinki (as revised in 2013). The protocol was reviewed and approved by the institutional review committee of Beijing Chaoyang Hospital (approval number: 2020-科-303), and individual consent for this retrospective analysis was waived.

\section{Organ procurement and allocation}

The allocation of organs abided by the Basic Principles and Core Policies of the Allocation and Sharing of Human Organs in China. The China Organ Transplant Response System (COTRS) was used for the allocation of organs.

\section{Operative procedures}

Modified piggyback orthotopic LT was conducted. A curved incision below the right costal margin was made, and in some cases, a Mercedes Benz incision was needed. Firstly, the perihepatic ligaments were separated, then the second porta hepatis was divided to expose the left, middle, and right hepatic vein. The next step was to skeletonize the proper hepatic artery, expose the hepatic artery's bifurcation upwards, and ligate and cut off the right and left hepatic arteries, respectively. The portal vein was then skeletonized, the left and right branches of the portal vein were cut off, then finally, the common hepatic duct was cut off. The next procedure following the separation of the first porta hepatis was to divide the short hepatic veins. The left and middle hepatic veins were cut off and sutured, the right hepatic vein was clipped and sheared off, and the liver was removed.

The stump of the right hepatic vein was trimmed, then the vein anastomosis between the stumps of the suprahepatic inferior vena cava of the donor liver and the right hepatic vein of the recipient was completed. Anastomosis the stump of the portal vein and then restore the hepatic blood flow. Anastomosis hepatic artery and extrahepatic biliary passages. The operation was completed after the placement of the drainage tube and closing incision.

\section{Immunosuppression}

Basiliximab (20 mg) was administered within 2 hours before the operation and the fourth day after the operation. Methylprednisolone $(500 \mathrm{mg})$ was used intraoperatively. The dose of methylprednisolone decreased progressively after LT. From the second day after the operation, immunosuppressive agents were given to recipients. The initial dose of tacrolimus, which was used most frequently, was $2 \mathrm{mg}$ twice per day. The dose was adjusted, or patients were given a combination of tacrolimus and mycophenolate mofetil according to the blood concentration and biochemical parameters. Hormones were prohibited in patients who were diagnosed with liver malignancy, and sirolimus was usually provided for these patients 1 month later.

\section{Definitions and diagnostic criteria}

\section{In-hospital death}

Recipients usually experienced a relatively longer hospital stay after LT, and we defined in-hospital death as follows: (I) patients died of complications after transplantation during their hospitalization without discharge from hospital; (II) patients who were rehospitalized or died without operation were excluded.

\section{Primary non-function (PNF)}

PNF was defined as post-transplant liver dysfunction requiring re-transplantation or leading to death within 7 days. 


\section{Hemophagocytic syndrome (HPS)}

Diagnostic criteria fulfilled ( 5 out of the 8 criteria below):

(I) Fever which was more than $38.5^{\circ} \mathrm{C}$ and lasted for at least 7 days;

(II) Splenomegaly;

(III) Cytopenias (affecting $\geq 2$ of 3 lineages in the peripheral blood): hemoglobin $<90 \mathrm{~g} / \mathrm{L}$, platelets $<100 \times 10^{9} / \mathrm{L}$, neutrophils $<1.0 \times 10^{9} / \mathrm{L}$;

(IV) Hypertriglyceridemia and/or hypofibrinogenemia: fasting triglycerides $\geq 3.0 \mathrm{mmol} / \mathrm{L}$, fibrinogen $\leq 1.5 \mathrm{~g} / \mathrm{L}$;

(V) Hemophagocytosis in bone marrow, spleen or lymph nodes, and no evidence of malignancy;

(VI) Low or absent natural killer (NK) cell activity;

(VII) Ferritin $\geq 500 \mathrm{mg} / \mathrm{L}$;

(VIII)Soluble CD25 (i.e., soluble IL-2 receptor) $\geq 2,400 \mathrm{U} / \mathrm{mL}$.

\section{Graft-versus-host disease (GVHD)}

There were no standard diagnostic criteria for GVHD after LT, though GVHD was highly suspected if the following criteria were fulfilled:

(I) Clinical manifestations including rash, fever, diarrhea, pancytopenia, and a normal liver function, which presented 2 to 8 weeks after LT;

(II) Epidermal necrolysis was found by skin biopsy;

(III) Chimerism was observed by pathological examination.

\section{Statistical analysis}

SPSS 16.0 (IBM, Chicago, Illinois, USA) was used for data analysis. Quantitative variables were analyzed with the Student's $t$-test according to data distribution. Categorical variables were analyzed using the Chi-square test or Fisher's exact test as appropriate. $\mathrm{P}$ values less than 0.05 were considered significant. The Kaplan-Meier method was used to calculate the rate of perioperative death. Univariate analyses were performed to identify risk factors for perioperative death, infection-related death, and PNF. After univariate analyses, variables with $\mathrm{P}$ values less than 0.05 were included in the multivariate logistic regression analysis to identify the independent factors associated with perioperative death, infection-related death, and PNF.

\section{Results}

\section{Recipient characteristics}

The data of 529 recipients who underwent LT in our hospital were collected and analyzed retrospectively. Modified piggyback orthotopic LT was performed for all cases, and all of the allografts were from donation after cardiac death (DCD). There were 416 male and 113 female recipients, with a mean age of $51.6 \pm 10.4$ years, ranging from 19 to 82 years. The mean BMI was $24.4 \pm 3.8 \mathrm{~kg} / \mathrm{m}^{2}$ (range, $15.4-38.5 \mathrm{~kg} / \mathrm{m}^{2}$ ), and a BMI of more than $30 \mathrm{~kg} / \mathrm{m}^{2}$ was found in 45 patients. Diabetes mellitus was confirmed in 197 patients, hypertension was found in 152 patients, and cardiopathy was found in 41 patients. The reasons for LT were as follows: hepatitis B virus (HBV)-associated liver failure in 283 cases, hepatitis C virus (HCV)-associated liver failure in 26 cases, hepatitis $\mathrm{E}$ virus (HEV)-associated liver failure in three cases, fulminant hepatic failure in 16 cases, alcoholic-associated liver failure in 42 cases, autoimmune hepatitis-induced liver failure in 38 cases, liver malignancy with/without liver failure in 46 cases, hepatolenticular degeneration in 17 cases, schistosomal cirrhosis in two cases, nonalcoholic steatohepatitis (NASH) in 19 cases, a congenital polycystic liver in ten cases, and liver failure after transplantation in 27 cases. The mean MELD score was 24.1 \pm 12.3 (range, 6.0-40.0), and the mean Child-Pugh score was $9.9 \pm 2.7$ (range, 5.0-15.0). The mean operative time and anhepatic phase times were $514.3 \pm 132.2 \mathrm{~min}$ (range, 240.0 1,320.0 $\mathrm{min}$ ) and 91.8 $32.4 \mathrm{~min}$ (range, 30.0-230.0 min), respectively. The mean intraoperative blood loss was $1,151.5 \pm 1,014.5 \mathrm{~mL}$ (range, 100.0-8,000.0 mL). The mean age gap between donor and recipient was $14.8 \pm 11.5$ years (range, $0-54.0$ years). ABO-incompatible LT was conducted in $54(10.2 \%)$ recipients.

\section{Donor characteristics}

Of the 529 donors, 434 were male, and 95 were female, and the mean age was $46.3 \pm 14.7$ years (range, $4-79$ years). The mean BMI was $24.6 \pm 3.6 \mathrm{~kg} / \mathrm{m}^{2}$ (range, $17.4-35.6 \mathrm{~kg} / \mathrm{m}^{2}$ ). The mean CIT was $6.2 \pm 2.7$ hours (range, 2.0-15.0 hours), and the mean WIT was 43.0 $\pm 1.2 \mathrm{~min}$ (range, 40-59 min). The last serum sodium and creatinine levels were $149.7 \pm 14.3 \mathrm{mmol} / \mathrm{L}$ (range, $125.0-187.7 \mathrm{mmol} / \mathrm{L}$ ) 
Table 1 Univariate analysis of factors related to perioperative death after liver transplantation

\begin{tabular}{|c|c|c|c|}
\hline Parameters & $\begin{array}{l}\text { Perioperative } \\
\text { death }(n=70)\end{array}$ & $\begin{array}{c}\text { No-death } \\
(\mathrm{n}=459)\end{array}$ & $P$ values \\
\hline Age, years & & & 0.258 \\
\hline$<60$ & 49 (12.3) & $350(87.7)$ & \\
\hline$\geq 60$ & $21(16.2)$ & $109(83.8)$ & \\
\hline Gender & & & 0.058 \\
\hline Male & $49(11.8)$ & $367(88.2)$ & \\
\hline Female & $21(18.6)$ & $92(81.4)$ & \\
\hline BMI, $\mathrm{kg} / \mathrm{m}^{2}$ & & & 0.820 \\
\hline$\leq 25$ & $44(13.5)$ & $282(86.5)$ & \\
\hline$>25$ & $26(12.8)$ & $177(87.2)$ & \\
\hline MELD score & & & $<0.001$ \\
\hline $6-10$ & $3(2.9)$ & $102(97.1)$ & \\
\hline $11-20$ & $9(7.4)$ & $113(92.6)$ & \\
\hline $21-30$ & $12(12.4)$ & $85(87.6)$ & \\
\hline $31-40$ & $46(22.4)$ & $159(77.6)$ & \\
\hline Child-Pugh grading & & & $<0.001$ \\
\hline A & $3(3.3)$ & $89(96.7)$ & \\
\hline B & $6(5.6)$ & $102(94.4)$ & \\
\hline $\mathrm{C}$ & $61(18.5)$ & $268(81.5)$ & \\
\hline Operative time, $\min$ & & & 0.928 \\
\hline$<360$ & $5(12.8)$ & $34(87.2)$ & \\
\hline $360-600$ & $51(13.0)$ & $342(87.0)$ & \\
\hline$>600$ & $14(14.4)$ & $83(85.6)$ & \\
\hline Intraoperative blood, $\mathrm{mL}$ & & & $<0.001$ \\
\hline$<2,000$ & $47(10.6)$ & $395(89.4)$ & \\
\hline$\geq 2,000$ & $23(26.4)$ & $64(73.6)$ & \\
\hline Anhepatic phase, min & & & 0.045 \\
\hline$\leq 60$ & $8(7.4)$ & $100(92.6)$ & \\
\hline$>60$ & $62(14.7)$ & $359(85.3)$ & \\
\hline \multicolumn{3}{|c|}{ Age gap between donor and recipient, years } & 0.062 \\
\hline$\leq 10$ & $19(8.4)$ & $208(91.6)$ & \\
\hline $10-20$ & 26 (16.6) & $131(83.4)$ & \\
\hline $21-30$ & 15 (15.8) & $80(84.2)$ & \\
\hline $31-40$ & 5 (17.9) & $23(82.1)$ & \\
\hline$>40$ & $5(22.7)$ & 17 (77.3) & \\
\hline
\end{tabular}

Table 1 (continued)
Table 1 (continued)

\begin{tabular}{lrrr}
\hline Parameters & $\begin{array}{r}\text { Perioperative } \\
\text { death }(\mathrm{n}=70)\end{array}$ & $\begin{array}{c}\text { No-death } \\
(\mathrm{n}=459)\end{array}$ & P values \\
\hline Incompatibility of ABO blood type & & 0.102 \\
Yes & $11(20.4)$ & $43(79.6)$ & \\
No & $59(12.4)$ & $416(87.6)$ & \\
\hline
\end{tabular}

The values were presented as number (\%). BMI, body mass index; MELD, model for end-stage liver disease.

and 106.4 $\pm 85.4 \mu \mathrm{mol} / \mathrm{L}$ (range, 21.1-924.0 $\mu \mathrm{mol} / \mathrm{L}$ ), respectively. Gender mismatch between donor and recipient occurred in 176 cases. The main cause of cardiac arrest in the DCD donors was cerebral hemorrhage, including spontaneous cerebral hemorrhage and traumatic intracranial hemorrhage.

\section{General characteristics of in-hospital deaths}

Of the 529 cases, in-hospital death was confirmed in 70 recipients, and the in-hospital mortality rate was $13.2 \%$. The causes for LT in the 70 recipients were as follows: $\mathrm{HBV}$-associated liver failure in 18 (25.7\%) cases, liver malignancy with/without liver failure in $24(34.3 \%)$ cases, alcoholic-associated liver failure in 10 (14.3\%) cases, HEV-associated liver failure in $1(1.4 \%)$ case, autoimmune hepatitis-induced liver failure in 7 (10.0\%) cases, schistosomal cirrhosis in $1(1.4 \%)$ case, congenital polycystic liver in $1(1.4 \%)$ case, and liver failure after transplantation in $5(7.1 \%)$ cases. A total of 65 patients underwent LT for the first time, and the remaining five patients received their first LT several years ago. A total of 7 recipients received reoperation for complications after LT, including debridement and hemostasis for three recipients and removal of intra-abdominal abscesses for four recipients. After LT, the survival time ranged from 6 hours to 84 days, with a median of 37 days.

\section{Risk factors of in-hospital death}

As shown in Table 1, the univariate analysis demonstrated that the MELD score before surgery was positively correlated with in-hospital death after LT. The mortality rates were $2.9 \%, 7.4 \%, 12.4 \%$, and $22.4 \%$ in patients with MELD scores of 6-10, 11-20, 21-30, and 31-40, respectively $(\mathrm{P}<0.001)$. Child-Pugh grading was also positively correlated with mortality, and the incidence 
Table 2 Multivariate analysis of risk factors related to perioperative death

\begin{tabular}{lccc}
\hline \multirow{2}{*}{ Risk factors } & \multicolumn{3}{c}{ Multivariate analysis of perioperative death } \\
\cline { 2 - 4 } & $\mathrm{RR}$ & $95 \% \mathrm{Cl}$ & $\mathrm{P}$ value \\
\hline MELD score & 1.775 & $1.231-2.560$ & 0.002 \\
Child-Pugh grading & 1.374 & $0.704-2.682$ & 0.352 \\
Intraoperative blood & 2.719 & $1.500-4.929$ & 0.001 \\
Anhepatic phase & 1.843 & $0.834-4.073$ & 0.131 \\
\hline
\end{tabular}

MELD, model for end-stage liver disease.

rates were $3.3 \%, 5.6 \%$, and $18.5 \%$ for grades $\mathrm{A}, \mathrm{B}$, and $\mathrm{C}$, respectively $(\mathrm{P}<0.001)$. Patients with intraoperative blood loss $\geq 2,000 \mathrm{~mL}$ had a significantly increased in-hospital mortality (26.4\% vs. $10.6 \%, \mathrm{P}<0.001)$. Although total operative time was not associated with mortality in this study, anhepatic phase $>60$ min led to a higher mortality rate $(14.7 \%$ vs. $7.4 \%$, $\mathrm{P}=0.045)$. The mortality rate increased as the age gap between donor and recipient increased; however, the age gap was not demonstrated to influence in-hospital death. In Table 2, the multivariate analysis showed that the MELD score $(\mathrm{P}=0.002)$ and intraoperative blood loss $(\mathrm{P}=0.001)$ were the two independent risk factors of in-hospital death.

\section{Causes of in-bospital death}

All patients died postoperatively for all 70 cases of inhospital death, and no intraoperative deaths were found. Several causes of in-hospital death after LT were detected in this study. The most common cause was an infection, including bacterial and fungal infections. Infectious death was confirmed in $24(34.3 \%)$ recipients. Of the 24 recipients, pulmonary fungal infection, as the fatal cause, was confirmed in 15 cases, while one of these cases was diagnosed with fungal pneumonia with HPS. As HPS was cured, fungal pneumonia was the cause of death. Concurrently, pulmonary and intra-abdominal infection, intra-abdominal infection, and intracranial infection were diagnosed in 5, 2, and 2 recipients, respectively. The second most common cause of in-hospital death was PNF, which was confirmed in $11(15.7 \%)$ recipients. The third cause of in-hospital death, multi-organ failure, was confirmed in 9 (12.9\%) recipients. As the fourth cause of death, cerebral hemorrhage was found in $8(11.4 \%)$ recipients. Myocardial infarction, intra-abdominal hemorrhage, GVHD, pulmonary embolism, and heart failure due to severe pulmonary hypertension were confirmed in 7 (10.0\%),
$3(4.3 \%), 3(4.3 \%), 2(2.9 \%)$, and $2(2.9 \%)$ recipients, respectively. HPS, as a cause of in-hospital death, was found in $1(1.4 \%)$ recipient (2 recipients encountered HPS, 1 died of it, the other died of fungal pneumonia).

\section{Analysis of pathogenic microorganisms}

Of the recipients who died of infection, Aspergillus fumigatus, Aspergillus flavus, and Cryptococcus neoformans were detected in 12, 2, and 1 case, respectively. Klebsiella pneumoniae was found in seven recipients, including carbapenem-resistant Klebsiella pneumoniae in five recipients. Acinetobacter baumannii was confirmed in seven recipients, methicillin-resistant Staphylococcus aureus in two recipients, Pseudomonas aeruginosa in five recipients, Stenotrophomonas maltophilia in three recipients, Escherichia coli in four recipients, Enterococcus faecium in four recipients, and Enterobacter cloacae in two recipients.

\section{Factor analysis of infectious deatb}

The results in Table 3 demonstrated that the MELD score was correlated with infectious death. The mean score was $33.7 \pm 8.7$ in the infectious death group, which was significantly higher than $23.6 \pm 12.3$ in the control group $(\mathrm{P}<0.001)$. The infectious death group had a higher ChildPugh score of $11.5 \pm 2.0$, and the score was $9.8 \pm 2.7$ in the control group $(\mathrm{P}=0.003)$. The intraoperative blood loss was $1,595.8 \pm 1,144.9 \mathrm{~mL}$ in the infectious death group and $1,130.3 \pm 1,004.3 \mathrm{~mL}$ in the control group $(\mathrm{P}=0.028)$. The multivariate analysis demonstrated that the MELD score was an independent risk factor of infectious death.

\section{Factor analysis of PNF}

The univariate analysis demonstrated that the following 
Table 3 Analysis of risk factors related to infectious death

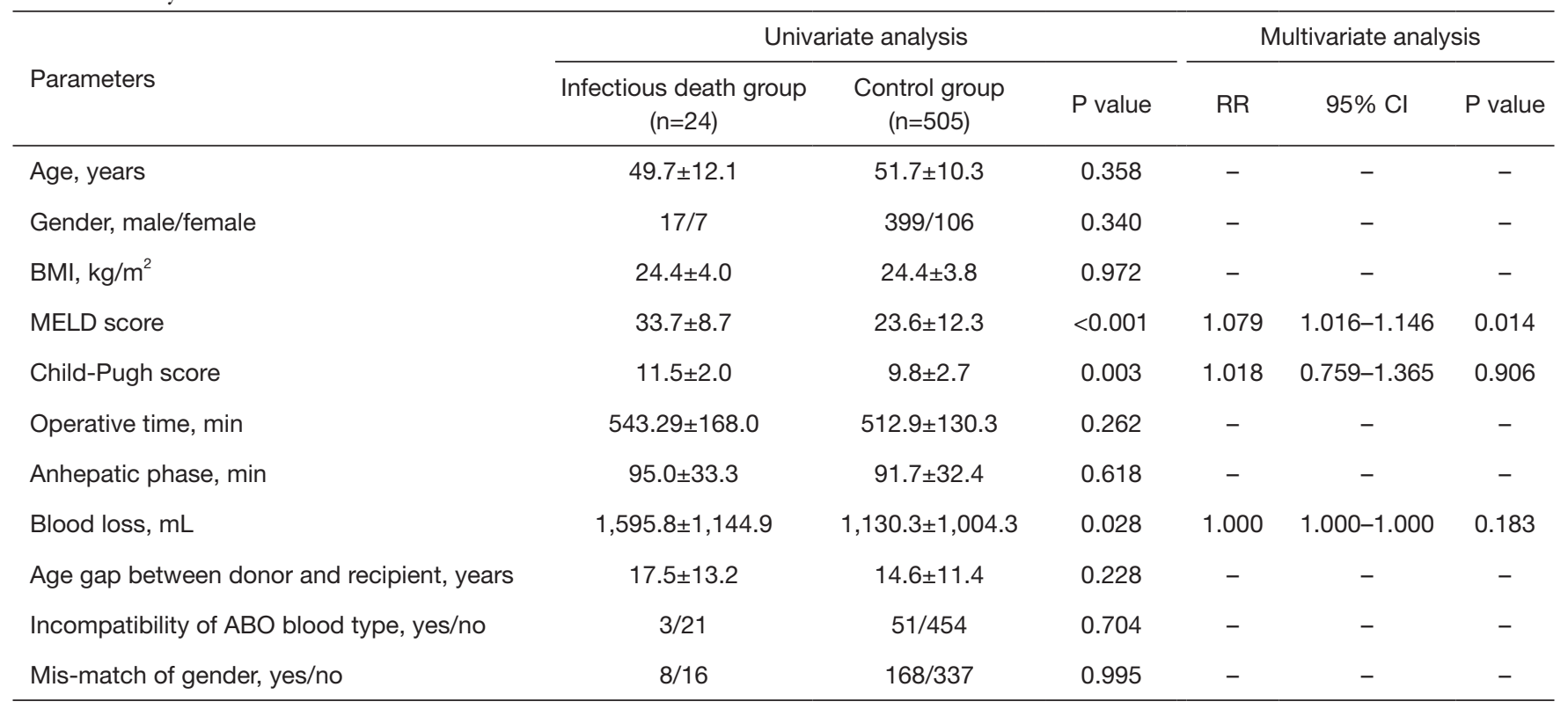

The values were presented as mean \pm standard deviation or number. BMI, body mass index; MELD, model for end-stage liver disease; $\mathrm{RR}$, relative risk; $\mathrm{Cl}$, confidence interval.

variables of donors were associated with the development of PNF: BMI $(\mathrm{P}=0.017)$, CIT $(\mathrm{P}<0.001)$, and WIT $(\mathrm{P}<0.001)$. A high level of creatinine $(\mathrm{P}=0.098)$ and $\mathrm{ABO}$ incompatibility $(\mathrm{P}=0.059)$ showed a tendency towards association with PNF. The multivariate analysis illustrated that the BMI of donors, CIT, and WIT were independent PNF risk factors (Table 4).

\section{Discussion}

LT has been considered the standard treatment for benign end-stage liver diseases and even for some liver tumors. The survival of recipients has improved markedly on account of the refinements in surgical techniques and postoperative care. However, immediate postoperative death still occurs for various reasons $(7,8)$. Recent studies have reported that in-hospital mortality ranged from $5 \%$ to $10 \%$ after LT (9). A study designed by Gil et al. (6) showed that the in-hospital mortality of deceased donor LT was $13.5 \%$, which was significantly higher than living donor LT. A new report by Molinari et al. (7) demonstrated that postoperative mortality was $9.1 \%$ within 90 days after cadaveric LT. The in-hospital mortality of recipients after cadaveric LT was $13.2 \%$ in our study, which was similar to the results of Gil et al.

Several factors of recipients have an impact on inhospital mortality. Nafea et al. (10) reported that MELD score, preoperative graft-recipient weight ratio, number of intraoperative blood transfusion units, postoperative alanine aminotransferase (ALT) levels, and postoperative total leukocyte counts were significant predictors for early mortality. Other studies have shown that factors of recipients, including high MELD scores (11), several comorbidities (12), advanced age (13), abnormal BMI (14), and low-performance status (15), were correlated with higher perioperative death after LT. In our study, we found that the MELD score influenced postoperative mortality. Child-Pugh grading, intraoperative blood loss, and anhepatic phase were also confirmed to be correlated with in-hospital death. Female recipients, or recipients who accepted a graft with a large age gap, seemed to have higher mortality, although no significant differences were confirmed. MELD score and intraoperative blood loss were confirmed as the independent risk factors of in-hospital death in this study.

Ten causes of death were summarized in our study, and the main cause was an infection, followed by PNF and multi-organ failure. Kusakabe et al. (16) found that the three leading causes of death after LT were sepsis, graft failure, and pulmonary complications. Kwak et al. (17) reported that the first three causes of death for recipients after LT were infection, recurrence of hepatocellular carcinoma, and graft failure, accounting for $34.8 \%, 18.3 \%$, and $15.0 \%$ of cases, 
Table 4 Analysis of risk factors related to PNF

\begin{tabular}{|c|c|c|c|c|c|c|}
\hline Factors & \multicolumn{3}{|c|}{ Univariate analysis } & \multicolumn{3}{|c|}{ Multivariate analysis } \\
\hline Age, years & $51.9 \pm 13.6$ & $46.2 \pm 14.8$ & 0.201 & - & - & - \\
\hline Gender, male/female & $3 / 8$ & $92 / 426$ & 0.416 & - & - & - \\
\hline BMI, kg/m² & $27.2 \pm 4.8$ & $24.6 \pm 3.5$ & 0.017 & 1.213 & $1.025-1.435$ & 0.025 \\
\hline Warm ischaemic time, min & $44.3 \pm 1.5$ & $43.0 \pm 1.2$ & $<0.001$ & 1.274 & $1.008-1.610$ & 0.043 \\
\hline $\begin{array}{l}\text { Age gap between donor and } \\
\text { recipient, years }\end{array}$ & $13.7 \pm 8.2$ & $14.8 \pm 11.6$ & 0.761 & - & - & - \\
\hline $\begin{array}{l}\text { Incompatibility of ABO blood } \\
\text { type, yes/no }\end{array}$ & $3 / 8$ & $51 / 467$ & 0.059 & - & - & - \\
\hline Last creatinine, $\mu \mathrm{mol} / \mathrm{L}$ & $148.6 \pm 78.5$ & $105.5 \pm 85.4$ & 0.098 & - & - & - \\
\hline
\end{tabular}

The values were presented as mean \pm standard deviation or number. BMI, body mass index; PNF, primary non-function; RR, relative risk; $\mathrm{Cl}$, confidence interval.

respectively. Different incidences of infection after LT have been reported. For example, Ayvazoglu Soy et al. (18) reported that the early postoperative infection rate in patients with LT was $23.3 \%$, while a study designed by Kawecki et al. (19) showed an infection rate of $27.2 \%$ within the first 4 weeks after LT. In some studies, infection was confirmed as the main cause for both short- and long-term death (20). Park et al. (21) reported that 57 (9.7\%) recipients who underwent living donor LT experienced infection within 1 month after surgery and 34 recipients lost their lives due to infection, and the incidence of infectious death was $5.7 \%$ (34/596). A study designed by Kwak et al. (17) demonstrated that pneumonia, which occurred in $46.3 \%$ of patients, was the most common cause of all infectious deaths. Infection was also confirmed as the main cause of inhospital death in our study, as infectious death was found in $34.3 \%$ of patients, which was similar to the results of Kwak et al. Pneumonia was responsible for most of the infectious deaths, and fungal pneumonia, which was confirmed in 15 cases, was the first lethal cause among the pneumonias. Fungal infection is not uncommon after LT. Some studies have demonstrated that the incidence of fungal infection in LT recipients ranged from $16 \%$ to $42 \%(22,23)$. Castaldo et al. (24) reported that the incidence of fungal infection after LT was $25.3 \%$ in 178 adult recipients, and $7.3 \%$ of adult recipients died of fungal infection. Additionally, they found that the most common site of fungal infection was the lung. The incidence of death induced by fungal infection was $2.8 \%$ in our study.

Previous studies have confirmed that factors including female gender, vancomycin-resistant Enterococcus colonization, a longer stay in the hospital, abdominal reoperation, mechanical ventilation $\geq 48$ hours, continuous renal replacement therapy, acute liver failure, re-transplantation, allograft rejection, induction of immunosuppression for the treatment of acute cellular rejection, long-term use of vascular and urinary catheters, a longer stay in the intensive care unit, higher MELD score, and elevated bilirubin levels were correlated with postoperative infection (25). However, factors that are correlated with infectious death have not been summarized in detail until now. Our study showed that higher MELD score, higher Child-Pugh score, and more intraoperative blood loss were correlated with a higher incidence of infectious death, and MELD score was confirmed as the independent risk factor of infectious death.

Primary graft dysfunction (PGD), which can be divided into PNF and early allograft dysfunction (EAD), also called initial poor function (IPF), is a severe event after LT. PNF is most often defined as either the need for retransplantation or the recipient's death within the first 7 days after LT. EAD is diagnosed based on elevated 
serum bilirubin, ALT, and aspartate transaminase levels and international normalized ratio level measured on the 2 nd to the 10th day after LT. The incidence of EAD ranges from $5.2 \%$ to $36.3 \%$, whereas the incidence of PNF ranges from $0.9 \%$ to $7.2 \%(26,27)$. Donor-related factors including age, nutritional status, fatty infiltration of the liver, and ischemia time and recipient-related factors including recipient status and transplantation type have been previously reported as risk factors for PGD (28-30). In our study, 2.1\% (11/529) of recipients died of PNF. The BMI of donors, CIT, and WIT were confirmed as the independent risk factors of PNF.

The shortcomings of our study were that the infection rates and the incidence rates of PGD for all recipients could not be calculated due to shortages in some records. Factors related to death causes apart from infection and PNF could not be analyzed exactly due to the small sample size. The collection and analysis of several other factors, including results of further laboratory examinations and characteristics of the recipient and donor-related causes of death, are needed in future studies.

In conclusion, the in-hospital mortality rate of recipients after LT was $13.2 \%$, and MELD score and intraoperative blood loss were determined as the two independent risk factors of in-hospital death. Infection was the main cause of death, followed by PNF. Furthermore, the risk factor for infection was the MELD score, and the BMI of donors, CIT, and WIT were independent risk factors of PNF.

\section{Acknowledgments}

Funding: None.

\section{Footnote}

Reporting Checklist: The authors have completed the STROBE reporting checklist. Available at http://dx.doi. org/10.21037/atm-20-5618

Data Sharing Statement: Available at http://dx.doi. org/10.21037/atm-20-5618

Peer Review File: Available at http://dx.doi.org/10.21037/ atm-20-5618

Conflicts of Interest: All authors have completed the ICMJE uniform disclosure form (available at http://dx.doi. org/10.21037/atm-20-5618). The authors have no conflicts of interest to declare.

Ethical Statement: The authors are accountable for all aspects of the work in ensuring that questions related to the accuracy or integrity of any part of the work are appropriately investigated and resolved. The study was conducted in accordance with the Declaration of Helsinki (as revised in 2013). The protocol was reviewed and approved by the institutional review committee of Beijing Chaoyang Hospital (approval number: 2020-科-303) and individual consent for this retrospective analysis was waived.

Open Access Statement: This is an Open Access article distributed in accordance with the Creative Commons Attribution-NonCommercial-NoDerivs 4.0 International License (CC BY-NC-ND 4.0), which permits the noncommercial replication and distribution of the article with the strict proviso that no changes or edits are made and the original work is properly cited (including links to both the formal publication through the relevant DOI and the license). See: https://creativecommons.org/licenses/by-nc-nd/4.0/.

\section{References}

1. Starzl TE, Groth CG, Brettschneider L, et al. Orthotopic homotransplantation of the human liver. Ann Surg 1968;168:392-415.

2. Adam R, Karam V, Delvart V, et al. Evolution of indications and results of liver transplantation in Europe. A report from the European Liver Transplant Registry (ELTR). J Hepatol 2012;57:675-88.

3. Kim WR, Lake JR, Smith JM, et al. OPTN/SRTR 2015 Annual Data Report: Liver. Am J Transplant 2017;17 Suppl 1:174-251.

4. Tan PS, Muthiah MD, Koh T, et al. Asian Liver Transplant Network Clinical Guidelines on Immunosuppression in Liver Transplantation. Transplantation 2019;103:470-80.

5. Bennett-Guerrero E, Feierman DE, Barclay GR, et al. Preoperative and intraoperative predictors of postoperative morbidity, poor graft function, and early rejection in 190 patients undergoing liver transplantation. Arch Surg 2001;136:1177-83.

6. Gil E, Kim JM, Jeon K, et al. Recipient Age and Mortality After Liver Transplantation: A Population-based Cohort Study. Transplantation 2018;102:2025-32.

7. Molinari M, Ayloo S, Tsung A, et al. Prediction of Perioperative Mortality of Cadaveric Liver Transplant Recipients During Their Evaluations. Transplantation 
2019;103:e297-307.

8. Rana A, Ackah RL, Webb GJ, et al. No Gains in Longterm Survival After Liver Transplantation Over the Past Three Decades. Ann Surg 2019;269:20-7.

9. Burroughs AK, Sabin CA, Rolles K, et al. 3-month and 12-month mortality after first liver transplant in adults in Europe: predictive models for outcome. Lancet 2006;367:225-32.

10. Nafea MA, Alsebaey A, Abd El Aal Sultan A, et al. Predictors of early recipient mortality after living donor liver transplantation in a tertiary care center in Egypt. Ann Saudi Med 2019;39:337-44.

11. Xia VW, Taniguchi M, Steadman RH. The changing face of patients presenting for liver transplantation. Curr Opin Organ Transplant 2008;13:280-4.

12. Petrowsky H, Rana A, Kaldas FM, et al. Liver transplantation in highest acuity recipients: identifying factors to avoid futility. Ann Surg 2014;259:1186-94.

13. Waits SA, Kim EK, Terjimanian MN, et al. Morphometric age and mortality after liver transplant. JAMA Surg 2014;149:335-40.

14. Barone M, Viggiani MT, Losurdo G, et al. Systematic review with meta-analysis: post-operative complications and mortality risk in liver transplant candidates with obesity. Aliment Pharmacol Ther 2017;46:236-45.

15. Dolgin NH, Martins PN, Movahedi B, et al. Functional status predicts postoperative mortality after liver transplantation. Clin Transplant 2016;30:1403-10.

16. Kusakabe J, Hata K, Tanaka S, et al. Prognostic index consisting of early post-transplant variables $<2$ weeks in adult living-donor liver transplantation. Hepatol Res 2020;50:741-53.

17. Kwak BJ, Kim DG, Han JH, et al. Clinical outcome of 1,000 consecutive cases of liver transplantation: a single center experience. Ann Surg Treat Res 2018;95:267-77.

18. Ayvazoglu Soy EH, Akdur A, Yildirim S, et al. Early Postoperative Infections After Liver Transplant. Exp Clin Transplant 2018;16 Suppl 1:145-8.

19. Kawecki D, Pacholczyk M, Lagiewska B, et al. Bacterial and fungal infections in the early post-transplantation period after liver transplantation: etiologic agents and their susceptibility. Transplant Proc 2014;46:2777-81.

20. Jain A, Reyes J, Kashyap R, et al. Long-term survival after liver transplantation in 4,000 consecutive patients at a single center. Ann Surg 2000;232:490-500.

21. Park J, Kim BW, Choi HJ, et al. Risk stratification for early bacteremia after living donor liver transplantation: a retrospective observational cohort study. BMC Surg 2020;20:2.

22. Grauhan O, Lohmann R, Lemmens P, et al. Fungal infections in liver transplant recipients. Langenbecks Arch Chir 1994;379:372-5.

23. Doria C, Bodzin AS, Vaccino S, et al. A retrospective analysis of the use of caspofungin in recipients of liver transplant with a modified high index of suspicion for fungal infection. A critical review of mortality, acute cellular rejection, infections, and changes in the liver function tests while on caspofungin. Clin Transplant 2011;25:569-75.

24. Castaldo P, Stratta RJ, Wood RP, et al. Clinical spectrum of fungal infections after orthotopic liver transplantation. Arch Surg 1991;126:149-56.

25. Kim SI. Bacterial infection after liver transplantation. World J Gastroenterol 2014;20:6211-20.

26. Pokorny H, Gruenberger T, Soliman T, et al. Organ survival after primary dysfunction of liver grafts in clinical orthotopic liver transplantation. Transpl Int 2000;13 Suppl 1:S154-7.

27. Uemura T, Randall HB, Sanchez EQ, et al. Liver retransplantation for primary nonfunction: analysis of a 20-year single-center experience. Liver Transpl 2007;13:227-33.

28. Johnson SR, Alexopoulos S, Curry M, et al. Primary nonfunction (PNF) in the MELD Era: An SRTR database analysis. Am J Transplant 2007;7:1003-9.

29. Cameron AM, Ghobrial RM, Yersiz H, et al. Optimal utilization of donor grafts with extended criteria: a singlecenter experience in over 1000 liver transplants. Ann Surg 2006;243:748-53; discussion 753-5.

30. Rull R, Vidal O, Momblan D, et al. Evaluation of potential liver donors: limits imposed by donor variables in liver transplantation. Liver Transpl 2003;9:389-93.
Cite this article as: Zhang XM, Fan $\mathrm{H}, \mathrm{Wu} \mathrm{Q}$, Zhang XX, Lang R, He Q. In-hospital mortality of liver transplantation and risk factors: a single-center experience. Ann Transl Med 2021;9(5):369. doi: 10.21037/atm-20-5618 